bereiten. In der Bakteriologie ist es aber, seitdem $R$. Koch auf den Plan trat; äblich geworden, nicht mit schönen Worten Gegenbeweise zu führen, sondern mit exakten, leicht nachzuprüfenden Experimenten. Und meine Experimente haben bewiesen,

1. da 3 der Seifenspiritus nur unsicher die Hand des Chirurgen von Keimen befreit,

2. da $B$ dagegen der Alkolıol, olne vorhergehende Waschung mit Seife, fast regelnüßig 99,9\% der Handbakterien in 3-5 Minuten unschädlich macht.

Diese experimentell bewiesenen Tatsaclien sind nunmehr seit sechs Jalıren, die zu 2. von Hunderten von Nacliprüfern, Bakteriologen wie baktoriologisch gebildeten (hirurgen, auf das bestimmteste erhärtet. Besonders auch die Tatsacle, da 3 die Alkoholwirkung im Experiment nicht auf Reste mitübertragenen Alkohols zu bezielıen ist, wie Sick, wieder ohne Experimente angestellt zu haben, annimmt. Diese Tatsacle wird und ist durch Kontrollversuche entschieden, wie ich sie in neiner Arbeit (Versuche 123-126) gleichfalls aufgefühi t, habe.

Damit ist diese Angelegenheit für micl erledigt. (Auch für uns an dieser Stelle. D. Red.)

\title{
Korrespondenzen.
}

\section{Alkohol und Seifenspiritus in der Händedesinfektion.} Erwiderung auf den Artikel von Sick in No. $2 \%$.

Von Generalarzt Prof. Dr. Schumburg in Hannover.

In dem oben bezeichneten Aufsatz unterzieht Sick meine Versuche über die Wirksamkeit des Seifenspiritus und des Alkohols bei der Händedesinfektion einer Kritik, deren Schlußfolgerungen bei denjenigen Lesern dieser Z $\mathrm{itschrift,} \mathrm{die} \mathrm{die} \mathrm{wissenschaftliche} \mathrm{Seite} \mathrm{der} \mathrm{Händedesinfektions-}$ frage nicht verfolgt haben, leicht zu falschell Auffassungen führen können und die ich deshalb richtig stellen muß.

Meine Versuche (Archiv für klin. (hirurgie Bd. 79, Heft 1) über Händedesinfektion mit Seifenspiritus ergaben, daß die keimentfernende Kraft des Seifenspiritus besonders wegen der Ungleichmäßigkeit der Wirkung nicht sehr hoch einzuschätzen ist. Sick glaubt, sich von dem Gegenteil überzeugt zu haben. Als Chirurg. Denn bakteriologische Versuche hat er nicht gemacht.

Siek hat vom Seifenspiritus die lediglich theoretische Meinung, daß ,eine antiseptisch imprägnierte, z. B. durch Seifenspiritus dauernd behandelte Háut den Bakterien keinen Nährboden mehr bieten kann".

Mit schönen Worten läßt sich ja trefflich streiten und ein Systen 